\title{
Dengue virus and host antibody - a dangerous balancing act
}

Brett A. Lidbury ${ }^{1}$ and Suresh Mahalingam ${ }^{2 \star}$

${ }^{1}$ John Curtin School of Medical Research, Australian National University, Australian Capital Territory, 0200, Australia; ${ }^{2}$ Institute for Glycomics, Griffith University, Gold Coast Campus, Queensland 4222, Australia

${ }^{*}$ Correspondence: SM (s.mahalingam@griffith.edu.au)

The mosquito-borne dengue virus (DEN) continues to be of intense concern to human health globally. This ongoing status is exacerbated by the lack of a vaccine. There have been many vaccines attempts, but success has been elusive; for example, recent large-scale trials with attenuated yellow fever virus - DEN chimeric vaccines to stimulate broad immunity against the four DEN serotypes have given largely disappointing results. ${ }^{1}$ In the Lancet Infectious Diseases, Osorio and colleagues report ${ }^{2}$ on their use of a DEN-2 live attenuated strain (DENVax-2) and the DENVax-2 molecular backbone to express prM and $E$ structural genes for serotypes 1, 3 and 4 to produce a tetravalent DEN vaccine representing each of the four DEN serotypes, with the goal of stimulating broad-based protective immunity. ${ }^{2}$ A placebo-controlled, randomised Phase 1 (safety and immunogenicity) study was conducted in a flavivirus naïve, healthy Colombian population living in a community located 2142 metres above sea level, far from DEN and its transmitting vector (Aedes aegypti).

The vaccine was well tolerated in study participants who received two high or two low doses via the intradermal or subcutaneous inoculation routes. The majority of participants sero-converted to three of the four serotypes (96\%), with a significant number (62\%) displaying antibody responses to all four DEN serotypes after the second dose. Vaccine viral RNA and infectious virus were detected in some participants. 
While encouraging, the spectre hovering over these phase 1 vaccine results is antibody-dependent enhancement (ADE) of DEN in individuals exposed to natural infection, and its association with dengue shock syndrome (DSS) and dengue haemorrhagic fever (DHF). ADE is observed at sub-neutralising titres of antiviral antibody, so ideally vaccines must drive strong, specific antibody responses to natural virus challenge and must sustain such responses to clear the infecting virus; this becomes a crucial balancing act.

ADE was first observed in vitro by Hawkes ${ }^{3}$ and an explanation for plaque enhancement proposed later by Kliks and Halstead. ${ }^{4}$ Early data suggested that ADE occurs in vivo, with the observation of enhanced viremia in monkeys experiencing a second dengue 2 infection. ${ }^{5} \mathrm{~A}$ fascinating aspect from the immunological standpoint were the observations of profound ADE in Fc-Receptor bearing cells such as blood monocytes and macrophages, normally seen as key to the host immune-mediated protection. Underpinning ADE in monocyte/macrophage cells, in addition to enhanced virus uptake, is the suppression of early inflammatory responses via disruption of specific transcription factor activity. ${ }^{6}$ How the disruption of early inflammatory gene expression impacts upon eventual adaptive immune responses must be an interest for vaccine developers pursuing ADE viruses like DEN, particularly for previously infected or vaccinated individuals.

Another imperative for DEN vaccine developers is understanding the physiological context of virus enhancement by $A D E$, dysregulation of early immune response and the desired post-vaccination outcome of side-effect free broad-based protection. Twenty-five years ago ADE in monocytes was identified as a risk factor for DSS/DHF in Thai children, ${ }^{7}$ while later studies showed no correlation of ADE with disease symptoms and viraemia. ${ }^{8}$ Careful studies by Vaughn and Libraty have shown that peak viremia correlated significantly with severe dengue disease. ${ }^{9,10}$

Osorio et al. (2) found that sero-conversion rates were quite variable for DEN-3 and DEN-4 after low- and high-dose tetravalent vaccination, which may flag danger for 
vaccinated individuals after subsequent natural DEN infection, with potentially heightened risk of DSS/DHF. One additional issue to consider is the phenomenon of viral interference, in which vaccine-induced antibody responses to certain dengue serotypes were reduced or obliterated, and it would be interesting to determine whether interference occurs with the vaccine trialled by Osorio. Returning to the "balancing act" between virus and antibody: this will involve thresholds of virus-antibody interaction and interaction of the virus-antibody complex with monocyte/macrophages via Fc-receptors, as well as the subsequent molecular cascades influencing the evolving DEN-specific host immunity, with the ultimate possibility of tipping towards host protection or virus enhancement. How this could unfold for flavivirus enhancement by cross-reactive antibodies is another permutation in these scenarios, most likely demanding a new immune fulcrum to drive the balance towards post-vaccination protection.

Dengue virus is a global health threat leading to 93 million cases per year, many serious. ${ }^{11}$ The seriousness of DEN and its disease on such a large scale requires that the push towards a vaccine is essential and must continue unperturbed. A tetravalent vaccine like the one presented by Osorio et al. is a sensible strategy given the nature of DEN serotype profile. The critical issue is that neutralizing antibodies after vaccination have not been shown to correlate with protection. Only a phase III efficacy study can demonstrate the performance of this vaccine. Given the potential of DSS/DHF for future vaccinees if the balance tips towards $A D E$, a possibility to consider is that before phase III studies are undertaken, participants given this vaccine should be challenged with each of the four live-attenuated viruses ${ }^{12}$ to assess DEN antibody profile as well as the ADE markers of in vitro growth enhancement and pro-inflammatory cytokine suppression. The technical expertise is available to facilitate the engineering of vaccine strains to induce the desired post-vaccination immune-mediated response, with the assessment of the knife-edge balance between successful protection from wild DEN infection, or the exacerbation of DEN disease, as the intellectual and scientific challenge ahead. 
Reference

1. Sabchareon A, Wallace D, Sirivichayakul C, Limkittikul K, Chanthavanich P, Suvannadabba S, Jiwariyavej V, Dulyachai W, Pengsaa K, Wartel TA, Moureau A, Saville M, Bouckenooghe A, Viviani S, Tornieporth NG, and Lang J. Protective efficacy of the recombinant, live-attenuated, CYD tetravalent dengue vaccine in Thai schoolchildren: a randomised, controlled phase $2 b$ trial. Lancet 2012; $\mathbf{3 8 0}$ : 1559-1567.

2. Osorio JE, Velez ID, Thomson C, Lopez L, Jimenez A, Haller AA, Silengo S, Scott J, Boroughs KL, Stovall JL, Luy BE, Arguello J, Beatty ME, Santangelo J, Gordon GS, Huang CYH, and Stinchcomb DT. Safety and immunogenicity of a recombinant live attenuated tetravalent dengue vaccine (DENVax) administered to flavivirus-naïve healthy adults in colombia: a randomized, placebo-controlled phase 1 study. Lancet Infect Dis (in press)

3. Hawkes RA and Lafferty KJ. The enhancement of virus infectivity by antibody. Virology 1967; 33: 250-261.

4. Kliks S, Halstead SB. An explanation for enhanced virus plaque formation in chick embryo cells. Nature 1980; 285: 504-505.

5. Halstead SB, Shotwell H, and Casals J. Studies on the pathogenesis of dengue infection in monkeys. II. clinical laboratory responses to heterologous infection. $J$ Infect Dis 1973; 128: 15-22.

6. Halstead S, Mahalingam S, Marovich MA, Ubol S, and Mosser DM. Intrinsic antibody-dependent enhancement of microbial infection in macrophages: disease regulation by immune complexes. Lancet Infect Dis 2010;10: 712-22.

7. Kliks SC, Nisalak A, Brandt WE, Wahl L, and Burke DS. Antibody-dependent enhancement of dengue virus growth in human monocytes as a risk factor for dengue hemorrhagic fever. Am J Trop Med Hyg.1989; 40: 444-451.

8. Laoprasopwattana K, Libraty DH, Endy TP, Nisalak A, Chunsuttiwat S, Vaughn DW, Reed G, Ennis FA, Rothman AL, and Green S. Dengue Virus (DV) enhancing antibody activity in preillness plasma does not predict subsequent 
disease severity or viremia in secondary DV infection. J Infect Dis 2005; 192: 510-519.

9. Vaughn DW, Green S, Kalayanarooj S, Innis BL, Nimmannitya S, Suntayakorn S, Endy TP, Raengsakulrach B, Rothman AL, Ennis FA, and Nisalak A. Dengue viremia titer, antibody response pattern, and virus serotype correlate with disease severity. J Infect Dis 2000;181: 2-9.

10. Libraty DH, Endy TP, Houng HS, Green S, Kalayanarooj S, Suntayakorn S, Chansiriwongs W, Vaughn DW, Nisalak A, Ennis FA, and Rothman AL. Differing influences of virus burden and immune activation on disease severity in secondary dengue-3 virus infections. J Infect Dis 2002; 185: 1213-1221.

11. Bhatt S, Gething PW, Brady OJ, Messina JP, Farlow AW, Moyes CL, Drake JM, Brownstein JS, Hoen AG, Sankoh O, Myers MF, George DB, Jaenisch T, Wint GR, Simmons CP, Scott TW, Farrar JJ, and Hay SI. The global distribution and burden of dengue. Nature 2013; 496: 504-507.

12. Halstead SB. Identifying protective dengue vaccines: Guide to mastering an empirical process. Vaccine 2013; 31: 4501-4507. 